\title{
Seismic velocity structure at the southern termination of the 2016 Kumamoto Earthquake rupture, Japan
}

\author{
Yasuhira Aoyagi ${ }^{*}$ D, Haruo Kimura and Kazuo Mizoguchi
}

\begin{abstract}
The earthquake rupture termination mechanism and size of the ruptured area are crucial parameters for earthquake magnitude estimations and seismic hazard assessments. The 2016 Mw 7.0 Kumamoto Earthquake, central Kyushu, Japan, ruptured a 34-km-long area along previously recognized active faults, eastern part of the Futagawa fault zone and northernmost part of the Hinagu fault zone. Many researchers have suggested that a magma chamber under Aso Volcano terminated the eastward rupture. However, the termination mechanism of the southward rupture has remained unclear. Here, we conduct a local seismic tomographic inversion using a dense temporary seismic network to detail the seismic velocity structure around the southern termination of the rupture. The compressional-wave velocity (Vp) results and compressional- to shear-wave velocity (Vp/Vs) structure indicate several E-W- and ENE-WSWtrending zonal anomalies in the upper to middle crust. These zonal anomalies may reflect regional geological structures that follow the same trends as the Oita-Kumamoto Tectonic Line and Usuki-Yatsushiro Tectonic Line. While the 2016 Kumamoto Earthquake rupture mainly propagated through a low-Vp/Vs area (1.62-1.74) along the Hinagu fault zone, the southern termination of the earthquake at the focal depth of the mainshock is adjacent to a 3-km-diameter high-Vp/Vs body. There is a rapid $5-\mathrm{km}$ step in the depth of the seismogenic layer across the $\mathrm{E}-\mathrm{W}$-trending velocity boundary between the low- and high-Vp/Vs areas that corresponds well with the Rokkoku Tectonic Line; this geological boundary is the likely cause of the dislocation of the seismogenic layer because it is intruded by serpentinite veins. A possible factor in the southern rupture termination of the 2016 Kumamoto Earthquake is the existence of a high$\mathrm{V} / \mathrm{Vs}$ body in the direction of southern rupture propagation. The provided details of this inhomogeneous barrier, which are inferred from the seismic velocity structures, may improve future seismic hazard assessments for a complex fault system composed of multiple segments.
\end{abstract}

Keywords: 2016 Kumamoto earthquake sequence, Seismic velocity structure, Rupture termination, Inhomogeneous barrier, Futagawa and Hinagu faults

\section{Introduction}

The barriers that stop earthquake rupture may be broadly classified into two groups: geometric and inhomogeneous barriers (Aki 1979). Geometric barriers, such as fault bends, are well known, and play important roles in both terminating rupture and initiating the rupture process during many earthquakes (e.g., King and Nabelek 1985).

\footnotetext{
*Correspondence: y-aoyagi@criepi.denken.or.jp

Central Research Institute of Electric Power Industry, 1646 Abiko,

Abiko-shi, Chiba 270-1194, Japan
}

Inhomogeneous barriers, such as seismic velocity anomalies and fault structures that cross the earthquake rupture zone, are also observed. For example, an oblique $4 \%$ high-velocity anomaly that crosses the San Andreas Fault at $10-30 \mathrm{~km}$ depth may have acted as a part of the barrier that stopped the southward rupture of the 1906 San Francisco Earthquake (Aki 1979). Pre-existing lengthy cross-structures in the northern-central Apennines, Italy, acted as persistent barriers during some historical earthquakes (Pizzi and Galadini 2009). The southward propagation of rupture during the 2019 Ridgecrest Earthquake, 
California, terminated at the Garlock Fault, which crosses the earthquake rupture zone, with no aftershocks observed to the south of the fault; Toda and Stein (2019) proposed that the no-seismicity area is composed of different rocks than the material to the north of the Garlock Fault. However, the details of such inhomogeneous barriers remain unclear.

The $2016 \mathrm{Mw}$ 7.0 Kumamoto Earthquake, central Kyushu, Japan, produced an approximately $34-\mathrm{km}$-long surface rupture that extended along the eastern part of the Futagawa fault zone and northernmost part of the Hinagu fault zone (Fig. 1; Shirahama et al. 2016). The rupture progressed into Aso Caldera, extending 4-5 km beyond the eastern end of the mapped Futagawa fault zone (Loc. 1, Fig. 1); many researchers have proposed that a magma chamber beneath Aso Caldera restrained the eastward propagation of earthquake rupture based on the negative gravity anomaly, low-seismic-velocity zone, high

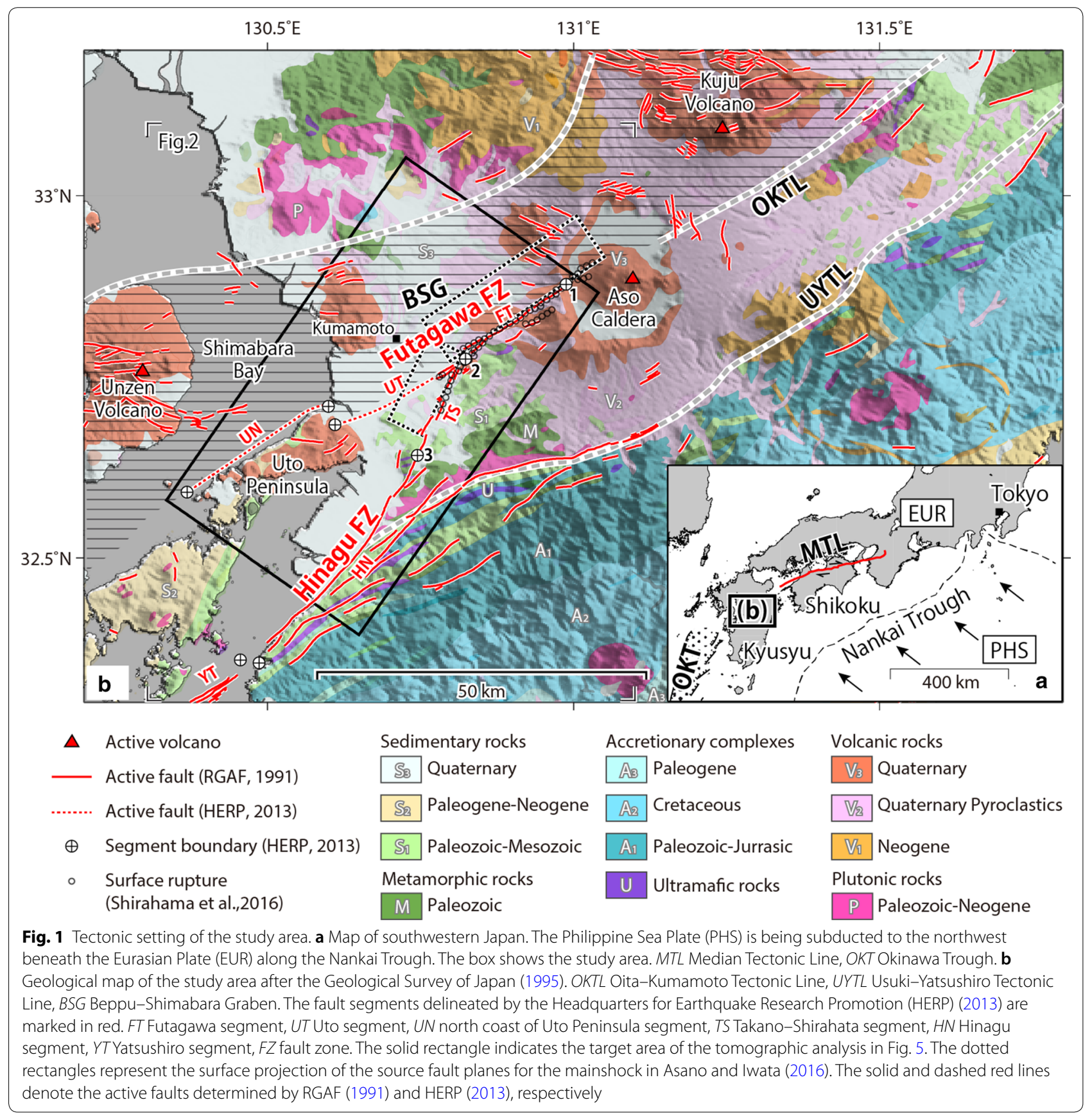


Poisson's ratio, high seismic attenuation, and high conductivity in this area (e.g., Miyakawa et al. 2016; Yue et al. 2017). However, the southern extent of the rupture vanished along the southern part of the Takano-Shirahata segment and did not reach the boundary with the Hinagu segment (Loc. 3, Fig. 1). Shito et al. (2017) proposed that the high-seismic-velocity body in the seismogenic layer might have suppressed the southward propagation of the rupture due to its high strength. Matsumoto et al. (2016) showed that the gravity anomaly corresponded to a geological boundary across the fault zone that controlled the spatial extent of the source fault. Nevertheless, there is insufficient information to fully constrain the subsurface structures and to elucidate the factors involved in terminating the southward propagation of earthquake rupture.

A maximum earthquake magnitude of 7.8-8.2 is predicted if the Futagawa and Hinagu fault zones rupture simultaneously (Headquarters for Earthquake Research Promotion (HERP) 2013). It is therefore important to know why the 2016 earthquake rupture was suppressed within particular segments, such that a more accurate assessment of the potential seismic hazards in the region can be obtained. Here, we conduct a tomographic inversion using observations from a dense temporary seismic network to constrain the seismic velocity structure around the southern termination of the earthquake rupture, and then propose the possible mechanisms of rupture termination via a comparison of geological structures and rock properties.

\section{Tectonic setting}

The Usuki-Yatsushiro Tectonic Line (UYTL) and OitaKumamoto Tectonic Line (OKTL) run approximately ENE-WSW across the middle of Kyushu Island, which includes the source area of the 2016 Kumamoto Earthquake (Fig. 1). These tectonic lines may connect in the east with the Median Tectonic Line (MTL) on Shikoku Island. The UYTL is remarkable in that it can be detected based on the surrounding landforms; it divides the postPaleozoic accretionary complexes in the south from metamorphic, plutonic, and sedimentary rocks in the north (Saito et al. 2010).

The OKTL, located $20 \mathrm{~km}$ northwest of the UYTL, is a major tectonic line with the distribution of preTertiary basement rocks restricted to its southern side (Yabe 1925). The OKTL is characterized by a steep gravity gradient and $20-30-\mathrm{km}$-wide negative anomalies on its northern side. These negative anomalies represent the Beppu-Shimabara Graben (BSG; Matsumoto 1979), which is a complex of volcano-tectonic depressions that includes active volcanoes, such as Kuju, Aso, and Unzen. The volcano-tectonic depressions in the Hohi volcanic zone, in the eastern part of the BSG, have been forming in a N-S extensional tectonic environment over the last 6 Ma (Kamata 1989). Kamata and Kodama (1994) proposed that this extensional tectonic environment resulted from oblique subduction of the Philippine Sea Plate beneath southwestern Japan. However, another explanation is that the $\mathrm{N}-\mathrm{S}$ extensional environment resulted from back-arc spreading in the Okinawa Trough, to the west of Kyushu Island (e.g., Kimura 1983; Tada 1984). The present stress field, which is based on focal mechanism solutions, also indicates that $\mathrm{N}-\mathrm{S}$ extension and normal faulting are dominant in this area (Matsumoto et al. 2015).

The Futagawa fault zone forms the western part of the OKTL. The Uto segment (UT) and north coast of the Uto segment (UN) are now incorporated within the Futagawa fault zone since the steep gravity gradient along the OKTL extends westward beyond the Futagawa segment (FT) and normal faulting is deforming the seafloor off the northern coast of Uto Peninsula (Fig. 1; HERP 2013). The Hinagu fault zone also consists of three segments based on its faulting history and geometry: the Takano-Shirahata (TS), Hinagu (HN), and Yatsushiro Sea (YT) segments (Fig. 1; HERP 2013).

\section{The southern termination of the 2016 Kumamoto Earthquake rupture}

The 2016 Kumamoto Earthquake sequence began with a foreshock (Mw 6.2) at 21:26 JST on April 14 and reached its climax with the mainshock (Mw 7.0) at 01:25 JST on April 16. Numerous source fault models have been proposed via inversion analyses of strong ground motion data and/or crustal deformation (e.g., Asano and Iwata 2016; Himematsu and Furuya 2016; Kobayashi 2017; Kobayashi et al. 2018), and most of them agree on the following points: the foreshock was characterized by rightlateral strike slip on a nearly vertical fault plane along the TS; the mainshock occurred on northwestward dipping fault planes along the FT and TS (e.g., Asano and Iwata 2016; Figs. 1 and 2); the rupture started from the deep portion of the fault plane near the junction of the Futagawa and Hinagu faults (Loc. 2 in Figs. 1 and 2), and then continued to mainly propagate eastward along a $60-70^{\circ}$ NW-dipping plane along the FT; and the slip along this plane was characterized by right-lateral strike slip with a normal slip component. Rupture also propagated southward along a $70-80^{\circ} \mathrm{WNW}$-dipping plane along the TS by almost pure right-lateral strike slip. This fault plane is different from that of the foreshock at depth; however, the magnitude estimated from its crustal movement is not negligible (Mw 6.73; Kobayashi et al. 2018), even though the amount of slip on this plane is smaller 


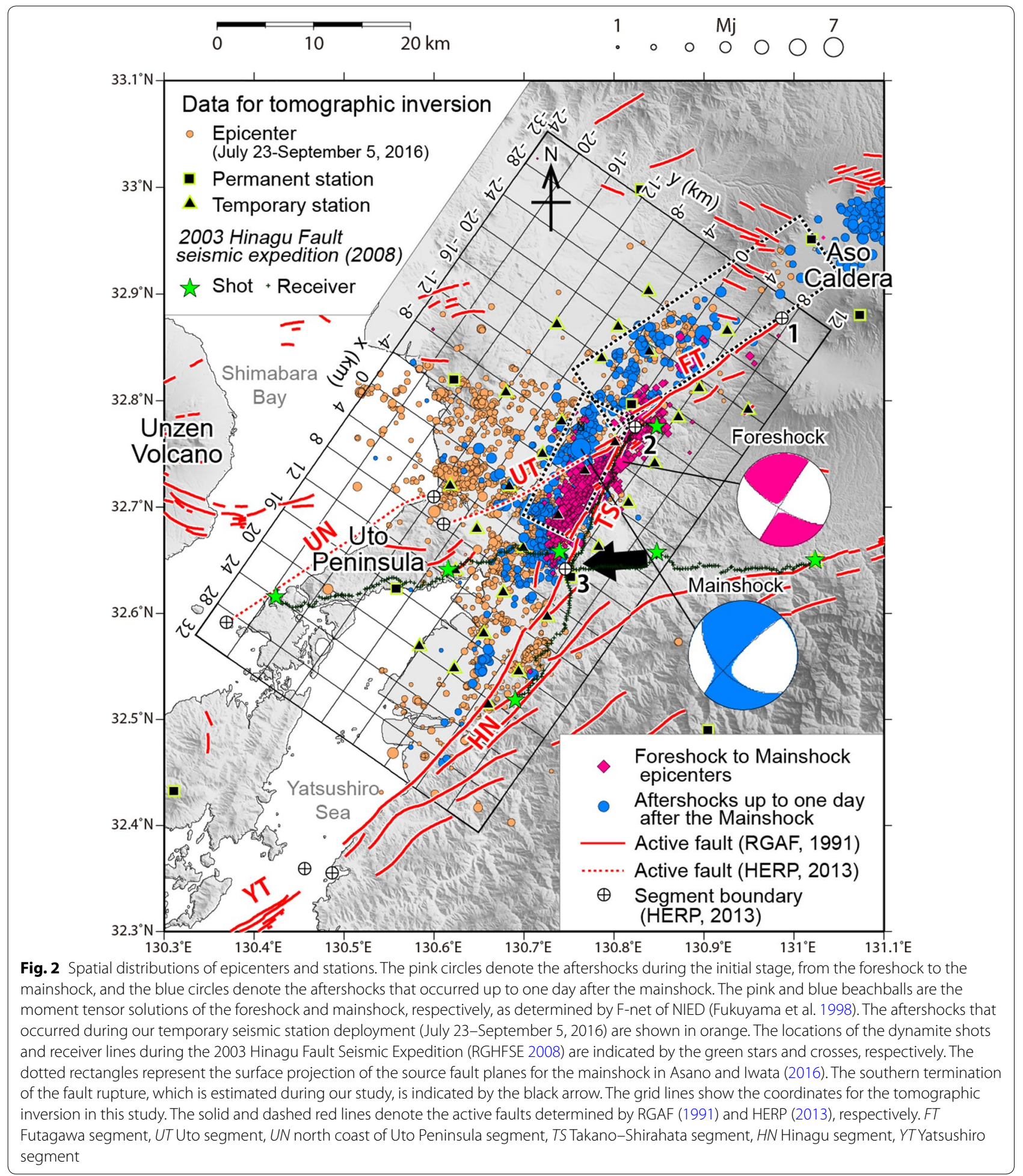

than that along the Futagawa Fault. Although the aftershock area expanded with time, its southern margin was located near the boundary between TS and HN during the initial stage immediately after the mainshock (Loc.
3 in Fig. 2). We hereafter identify the southern margin (black arrow in Fig. 2) as the southern termination of earthquake rupture. 


\section{Aftershock observations and tomographic inversion}

We deployed 30 offline seismic stations at an approximately $5-\mathrm{km}$ spacing across the Kumamoto Earthquake source area from late July to early September 2016. This temporary seismic network was designed to cover the aftershock area and complement the data from the surrounding permanent stations (Fig. 2). Continuous waveform data were recorded using a three-component KVS-300 2-Hz velocity sensor that was paired with an EDR-X7000 data logger at each temporary station. We selected the aftershocks that were listed in the Japan Meteorological Agency (JMA) unified earthquake catalog during this period for our analysis; the compressional(P-) and shear-wave (S-wave) first arrivals were automatically picked from the waveforms using the WIN system (Urabe and Tsukada 1991). The first-arrival data from the surrounding permanent stations were also integrated with these data. We first used the HYPOMH program (Hirata and Matsu'ura 1987) to determine the provisional hypocenter locations for events with more than $10 \mathrm{P}$ - and $\mathrm{S}$-wave first-arrival picks, assuming a simple two-layer model (Fig. 3). We also employed FPFIT (Reasenberg and Oppenheimer 1985) to determine the focal mechanism solutions using the P-wave first-motion polarities.

We then simultaneously determined the hypocenter locations and a three-dimensional seismic velocity model using the double-difference tomography method (tomoDD) developed by Zhang and Thurber (2003). The double-difference algorithm, which was originally developed by Waldhauser and Ellsworth (2000) to determine precise hypocenter locations, uses both absolute and differential travel-time data to reduce the systematic

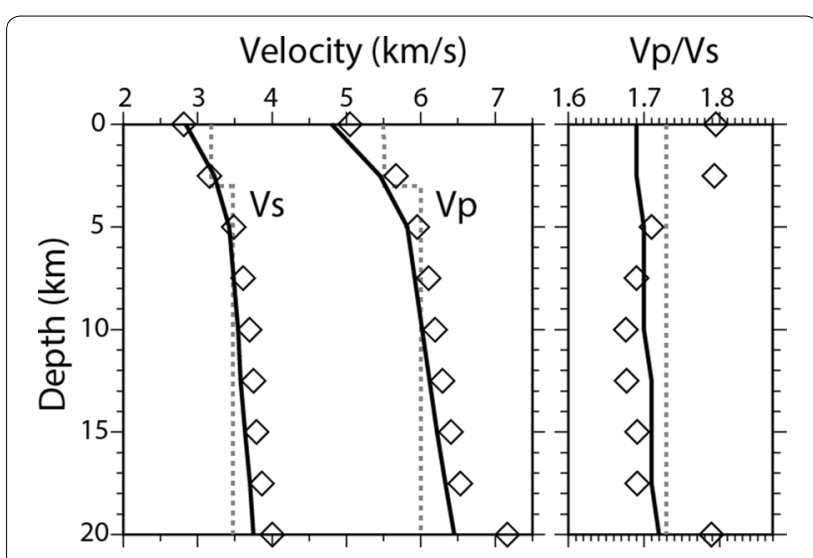

Fig. 3 Initial and final velocity models in this study. Solid lines=initial 1-D models used for the tomography, based on JMA2001 (Ueno et al. 2002). Dotted lines $=$ tentative 1-D models used to determine the

initial hypocenter locations. Diamonds = mean velocity in each depth layer that was acquired by the tomographic inversion errors associated with common ray paths from adjacent event pairs at each station. The double difference is the residual between the observed and calculated differential travel times of two nearby events at a given seismic station. The residuals between the observed and theoretical travel-time differences (or double differences) are minimized for the earthquake pairs at each station while linking together all of the observed event-station pairs in the program (Waldhauser and Ellsworth 2000).

We used the absolute and differential travel times from 1710 observed earthquakes that possessed provisional location errors of $<1 \mathrm{~km}$ for our tomographic inversion. We also included the P-wave travel times acquired during a seismic refraction/reflection experiment across the Hinagu fault zone in 2003 (Research Group for the 2003 Hinagu Fault Seismic Expedition (RGHFSE) 2008) as absolute data; the waveforms were produced from seven dynamite shots that were recorded by two lines of vertical-component receivers (129 along a N-S line and 230 along an E-W line) (Fig. 2). We used 78569 P-wave and 76334 S-wave absolute travel times, and $346106 \mathrm{P}$-wave and $277376 \mathrm{~S}$-wave differential travel times in the analysis. The $\mathrm{x}$-axis of the inversion grid was set at $\mathrm{N} 215 \mathrm{E}$ (along the fault zone), and the y-axis was set perpendicular to the fault zone (Fig. 2). The grid spacings were $4 \mathrm{~km}$ in the horizontal direction and $2.5 \mathrm{~km}$ in the vertical direction. The one-dimensional (1-D) velocity model JMA2001 (Ueno et al. 2002), which is used for routine hypocenter determinations at JMA, was applied as an initial velocity model (Fig. 3). The weighted root-meansquare (RMS) travel-time residual was reduced from 0.153 to $0.047 \mathrm{~s}$ after 32 iterations.

We conducted a checkerboard resolution test (CRT) to assess the resolution of the tomographic inversion. Synthetic data were constructed from the same sourcereceiver geometry as the observations. We assigned alternating $\pm 4 \%$ velocity perturbations to the grid nodes, and then calculated the travel times for the abovementioned initial model to generate synthetic data. We added random noise using a Gaussian distribution that corresponded to the picking errors, with $\mathrm{P}$ - and S-wave standard deviations of 0.1 and $0.2 \mathrm{~s}$, respectively. We then inverted the synthetic data using the same initial model. The CRT results for the $\mathrm{P}$ and $\mathrm{S}$ waves on horizontal sections are shown in Additional file 1: Figures S1 and Additional file 2: S2, respectively. Besides, three vertical cross-sections close to the fault zone are also shown in Additional file 3: Figure S3. All CRT results preserve the seismic velocity structure over the $2.5-12.5 \mathrm{~km}$ depth range, illustrating the high degree of reliability in our inversion results at these depths. A derivative weighted sum (DWS), which indicates the ray-path density, is output at each grid node in the tomographic inversion. 
The well-resolved area in the CRT results corresponds well with the 500 DWS contours for both of the P and $\mathrm{S}$ waves. Therefore, we mask the area below the threshold in the following results. Little area meets the DWS thresholds at 0 and $15 \mathrm{~km}$ depth.

We also performed two cases of hypothesis testing to determine whether the feature described later is indeed present. In the first case, we generated a horizontally layered velocity model based on the mean velocity of each layer of the final 3-D model in Fig. 3. In the second case, we gave high $V \mathrm{p} / V \mathrm{~s}$ values on three grid nodes within the same horizontally layered velocity model to simulate inhomogeneous structure around the southern termination of earthquake rupture. We then calculated the travel times for each model to generate synthetic data and added random noise in the same way as CRT. We finally inverted each synthetic data using the same initial model as CRT. The hypothesis testing results for $V \mathrm{p} / V \mathrm{~s}$ are shown in Additional file 4: Figures S4. Case 1 preserves the homogeneous $V \mathrm{p} / V \mathrm{~s}$ structure over the $2.5-15 \mathrm{~km}$ depth range. On the other hand, case 2 reproduces high $V \mathrm{p} / V \mathrm{~s}$ patches at the three nodes given inhomogeneous values. The locations and velocities of the patches are consistent with those of the synthetic model. These results demonstrate the high $V \mathrm{p} / V \mathrm{~s}$ patch around the southern termination described later is not an inversion artifact arising from ray-path and/or station coverage.

\section{Results}

\section{Focal mechanism solutions}

A total of 762 good-quality focal mechanism solutions (azimuthal coverage $>0.5$, number of stations $>20$, misfit $<0.1$ ) are plotted in Fig. 4. Normal faulting is the predominant faulting style on the northern side of the UT, which is consistent with the formation of the BSG in the region. However, the nodal planes have different orientations from area to area. NW-SE-oriented faults dominate around the western edge of the source fault along the FT (area 1), whereas E-W-oriented faults dominate to the south of Mt. Kinbo (area 2) and along the northern coast of Uto Peninsula (area 3). Conversely, strike-slip faulting is the predominant faulting style on the southern side of the UT, especially near the Hinagu fault zone (area 4). This trend is very similar to those depicted before the 2016 Kumamoto Earthquake by Matsumoto et al. (2015), which would mean that the aftershocks should reflect the regional tectonic stress regime. However, the horizontal stress direction may have been rotated in area 1 by the Kumamoto Earthquake since a $\mathrm{N}-\mathrm{S}$ extensional stress regime was dominant across the entire area before the event. Goto et al. (2017) also showed that a static Coulomb stress change on NW-SE-striking normal faults

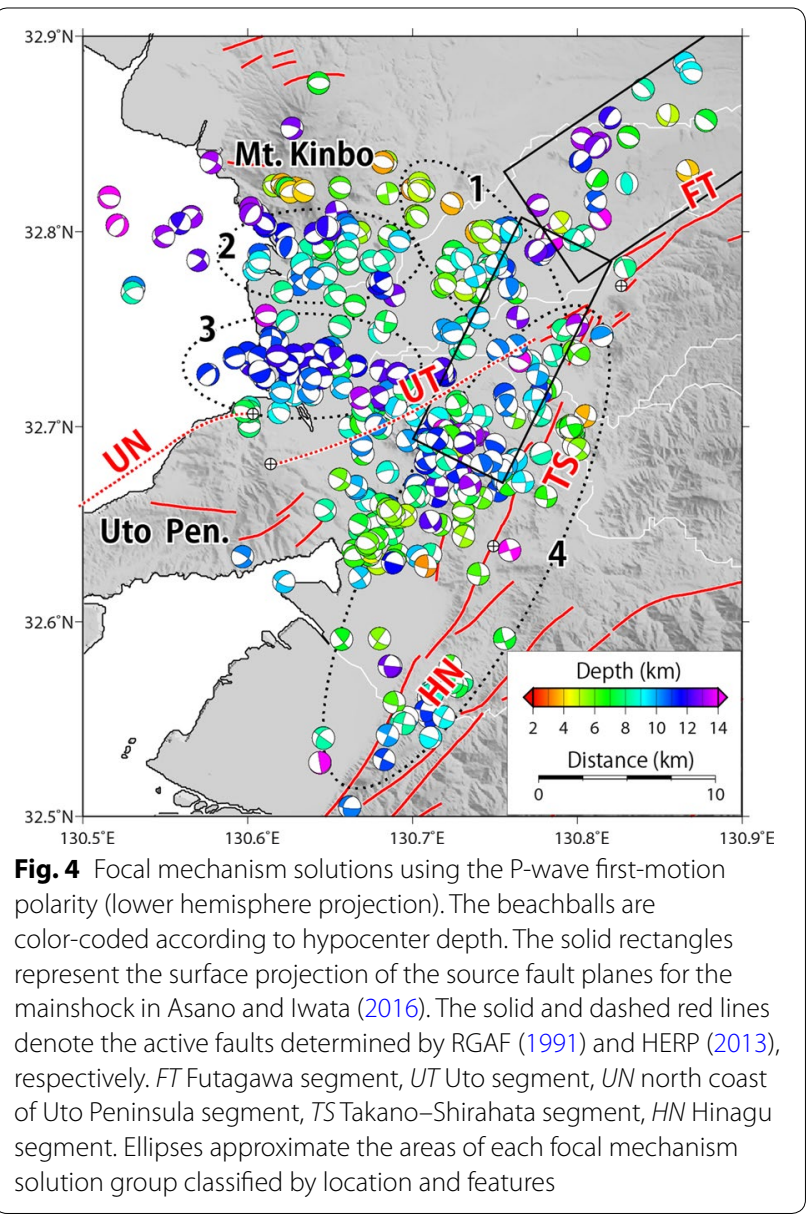

would have been promoted by the Kumamoto Earthquake in the area.

\section{$V p$ and $V s$ structures}

Figure 5 shows the P-wave velocity $(\mathrm{Vp})$ results for each depth and the surface geology. There is an approximately 5 -km-wide low-velocity anomaly at $2.5 \mathrm{~km}$ depth that runs ENE-WSW and is located between TS and UT. This anomaly may correspond to the base of the $S_{1}$ sedimentary rocks of the Mifune Group, which form a syncline that is also oriented ENE-WSW. Conversely, the highvelocity anomalies at $2.5 \mathrm{~km}$ depth are generally distributed on the southeastern side of the Futagawa-Hinagu fault zone, and may correspond to metamorphic rocks $(\mathrm{M})$ and granite $(\mathrm{P})$. The high-velocity anomalies at $5 \mathrm{~km}$ depth are still distributed on the southeastern side of the Futagawa-Hinagu fault zone, but they are only present as patches, such as $\mathrm{H} 1$ and $\mathrm{H} 2$. Patch $\mathrm{H} 1$ extends to the west and crosses the Hinagu Fault in the E-W direction. The velocity boundary between this high- $V \mathrm{p}$ anomaly and the northern low- $V \mathrm{p}$ anomaly corresponds well with the surface expression of the geological boundary between 

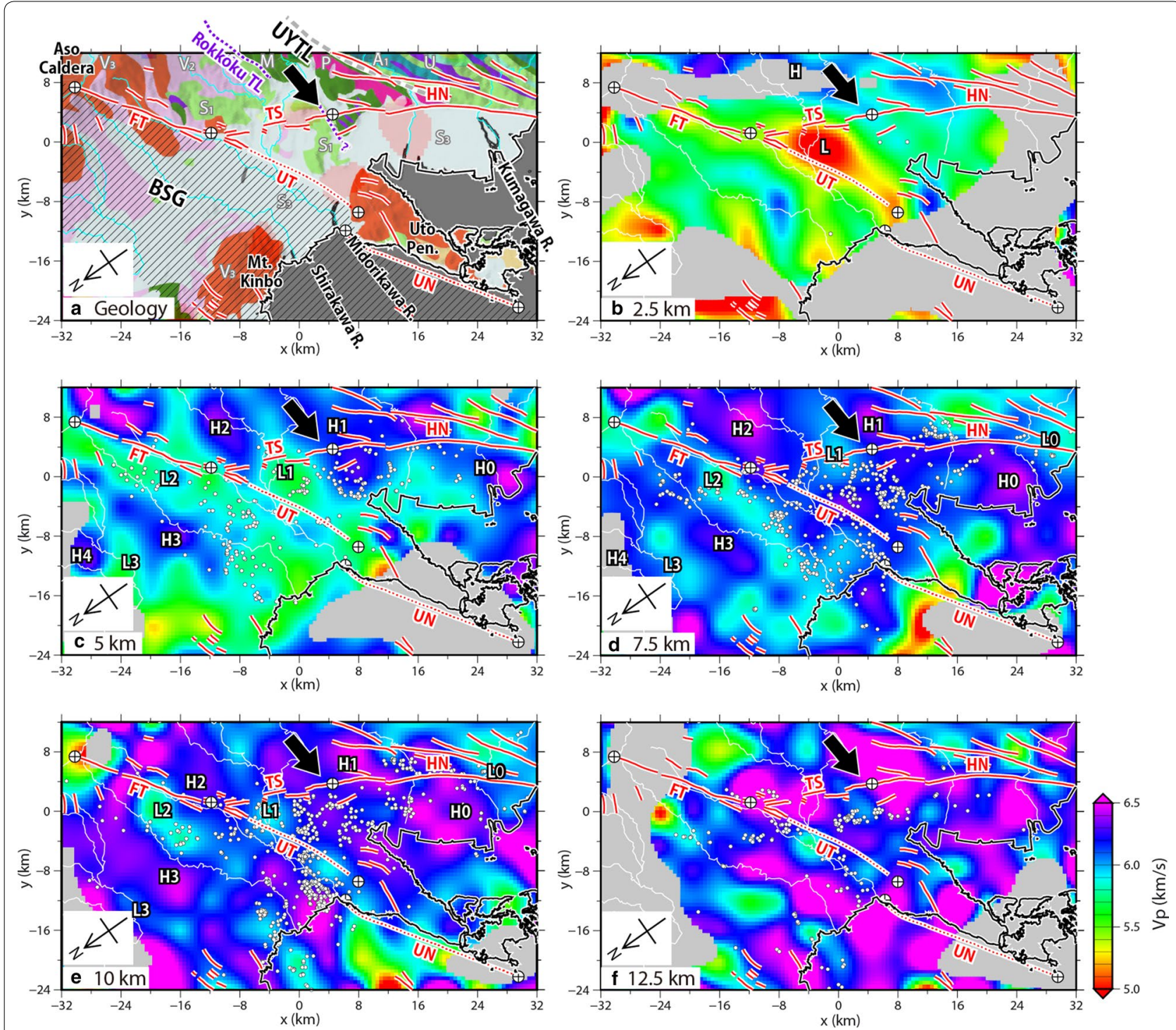

Fig. 5 P-wave velocity structure and relocated hypocenters in this study. a Surface geology and velocity structure at b $2.5 \mathrm{~km}, \mathbf{c} 5 \mathrm{~km}, \mathbf{d} 7.5 \mathrm{~km}$, e $10 \mathrm{~km}$, and $\mathbf{f} 12.5 \mathrm{~km}$ depth. The white circles indicate the relocated hypocenters within $2.5 \mathrm{~km}$ of each depth slice. The solid and dashed red lines denote the active faults determined by RGAF (1991) and HERP (2013), respectively. BSG Beppu-Shimabara Graben, UYTL Usuki-Yatsushiro Tectonic Line, FT Futagawa segment, UT Uto segment, UN north coast of Uto Peninsula segment, TS Takano-Shirahata segment, HN Hinagu segment. The geological classification in a is the same as in Fig. 1. LO- L4 and H0-H4 denote velocity anomalies (patches) that are discussed in the text. The southern termination of the fault rupture, which is estimated during our study, is indicated by the black arrow

metamorphic and sedimentary rocks (Fig. 5a). This geological boundary in its east extension is called the Rokkoku Tectonic Line, and it contains a 10- to 15-m-wide serpentinite body has intruded this zone. This tectonic line appears to have been recently reactivated as a fault because it contains noticeable fault gouge that runs parallel to the serpentinite zone (Yanagida 1958).

The high- or low-velocity anomalies, including patch $\mathrm{H} 1$, generally form elongate zones that are oriented E-W or ENE-WSW at $>5 \mathrm{~km}$ depth, respectively. The surface projections of the high-velocity $(\mathrm{H} 0-\mathrm{H} 4)$ and the low-velocity (L0-L4) anomalies are almost the same, regardless of depth (Fig. 5). Rivers tend to flow along the margins of the low-velocity anomalies, such as the upstream extent and mouth of the Shirakawa River, and the mouths of the Midorikawa and Kumakawa rivers (the anomalies are remarkable at $10 \mathrm{~km}$ depth). These observations suggest that the zonal bodies producing the velocity anomalies continue vertically and affect the landforms; they may also reflect regional geological structures 
that have the same strike. The relocated aftershocks tend to be concentrated along the margins of the zonal bodies on the northwestern side of the Futagawa-Hinagu fault zone. For example, there is a linear distribution of aftershocks from the mouth of the Shirakawa River to the junction of the Futagawa and Hinagu faults along the southern margin of L2 at $7.5 \mathrm{~km}$ depth. The focal mechanisms along the margins of the zonal bodies suggest that the structural boundaries between these bodies are normal faults (Fig. 4). Furthermore, perpendicular margins are found in some of the anomalies, with similar aftershock distributions along them. Consequently, the aftershocks were not uniformly distributed in space, but rather diverged from the junction of the Futagawa and Hinagu faults to the west in a fork-like pattern.

Figure S5 shows the $\mathrm{S}$-wave velocity $(V \mathrm{~s})$ results for each depth. A distinct low-velocity anomaly is distributed to the west from the junction of the Futagawa and Hinagu faults at $2.5 \mathrm{~km}$ depth. It is similar to the $V \mathrm{p}$ anomaly, but wider. Although elongate E-W or ENE-WSW zones of $V \mathrm{~s}$ anomalies are also found at $>5 \mathrm{~km}$ depth, they are less clear than the elongate zones of $V \mathrm{p}$ anomalies. We note that high- (low-) Vs anomalies are often found in the same areas where low- (high-) $V \mathrm{p}$ anomalies exist. For example, low- $V \mathrm{p}$ and high- $V \mathrm{~s}$ anomalies are present beneath Mt. Kinbo at $10 \mathrm{~km}$ depth, whereas there are high- $V \mathrm{p}$ (H1) and low- $V \mathrm{~s}$ anomalies at 7.5 and $10 \mathrm{~km}$ depth on the south side of the black arrow (Additional file 5: Figure S5). Such differences in $V p$ and $V$ s can be recognized more clearly in the $V \mathrm{p} / V \mathrm{~s}$ structure.

\section{$V p / V s$ structure and aftershock distribution in the early stage}

Figure 6 shows the $V \mathrm{p} / V \mathrm{~s}$ structure at each depth. The tension axes (T-axes) of the focal mechanisms mapped in Fig. 4 are also illustrated based on their fault types, which were classified according to the criteria outlined in Frohlich (1992). High- $V \mathrm{p} / V \mathrm{~s}$ areas are broadly spread at $2.5 \mathrm{~km}$ depth, with the main high- $V \mathrm{p} / V \mathrm{~s}$ anomaly found in the BSG, on the northern side of the Futagawa fault zone. These high- $V \mathrm{p} / V \mathrm{~s}$ anomalies may reflect highporosity rocks under low pressure. Elongate $\mathrm{E}-\mathrm{W}$ and ENE-WSW zonal anomalies are also clearly discernible in the $V \mathrm{p} / V \mathrm{~s}$ structure at $>5 \mathrm{~km}$ depth. We also plotted the early stage aftershocks in Fig. 6 using the JMA unified earthquake catalog. Although the JMA hypocenters are independent of our study, their spatial distribution shows a strong correlation with the $V \mathrm{p} / V \mathrm{~s}$ structure. Aftershocks mainly occurred in low- $V \mathrm{p} / V \mathrm{~s}$ areas. The hypocenters were concentrated in the low- $V \mathrm{p} / V \mathrm{~s}$ zone along the Hinagu fault zone during the initial stage immediately after the mainshock. The southern termination of the hypocenter distribution was cut off sharply at the boundary with the high- $V \mathrm{p} / V \mathrm{~s}$ anomaly at 7.5 and $10 \mathrm{~km}$ depth. Conversely, aftershocks occurred within the low$V \mathrm{p} / V \mathrm{~s}$ anomaly patch on the southern side of the boundary at $5 \mathrm{~km}$ depth.

\section{Discussion}

\section{Factors involved in earthquake rupture termination}

The depth section along the Hinagu fault zone clearly illustrates the relationship between the $V \mathrm{p} / V_{\mathrm{s}}$ structure and aftershock distribution during the early stage (Fig. 7). Aftershocks were limited to the low $-V \mathrm{p} / V \mathrm{~s}$ area at $7-15 \mathrm{~km}$ depth, which included the mainshock hypocenter, and they vanished at the boundary with the high- $V \mathrm{p} / V \mathrm{~s}$ body (marked ' $\mathrm{B}$ ' in Fig. 7). This velocity boundary is located $3 \mathrm{~km}$ to the south of the southern margin of the source fault plane in Asano and Iwata (2016). The amount of slip near the southern margin of the fault plane is $>1 \mathrm{~m}$ (Fig. $7 \mathrm{~b}$ ), which is consistent with the earthquake rupture reaching the boundary. Most of aftershocks on the southern side of the boundary were limited to shallower depths $(\sim 5 \mathrm{~km})$ above the high- $V \mathrm{p} / V \mathrm{~s}$ body, which means that the depth range of the seismogenic layer clearly changes across the boundary (Fig. 7c). We therefore conclude that the existence of a high $-V \mathrm{p} / V \mathrm{~s}$ body in the direction of rupture propagation was one factor that controlled rupture termination. This E-W-oriented velocity boundary corresponds well to surface expression of the Rokkoku Tectonic Line, as mentioned above. This tectonic line must extend to great depth to produce the observed vertical offset of the seismogenic layer; the serpentinite intrusion, which represents metamorphosed peridotite from the upper mantle, further supports a deep-seated fault.

Matsumoto et al. (2016) detected a NW-SE-trending subsurface structure that crossed the Hinagu fault zone at a geological boundary between metamorphic rocks and sedimentary rocks via gravity gradient analysis of the Bouguer anomalies. They concluded that this boundary controlled the spatial extent of the source fault since a planar subsurface structure, such as a fault, is discontinuous at the boundary. The location of their cross-structure coincides with the velocity boundary detected in our study, although the orientations are slightly different. Shito et al. (2017) detected a high-velocity body $(V \mathrm{p}=6.3 \mathrm{~km} / \mathrm{s}, V \mathrm{~s}=3.8 \mathrm{~km} / \mathrm{s})$ $5-15 \mathrm{~km}$ to the south of the mainshock hypocenter via a local tomographic inversion. They used the arrivaltime data for the Kumamoto aftershocks recorded by their own temporary network and other local crustal events during the 1996-2016 period. They suggested 

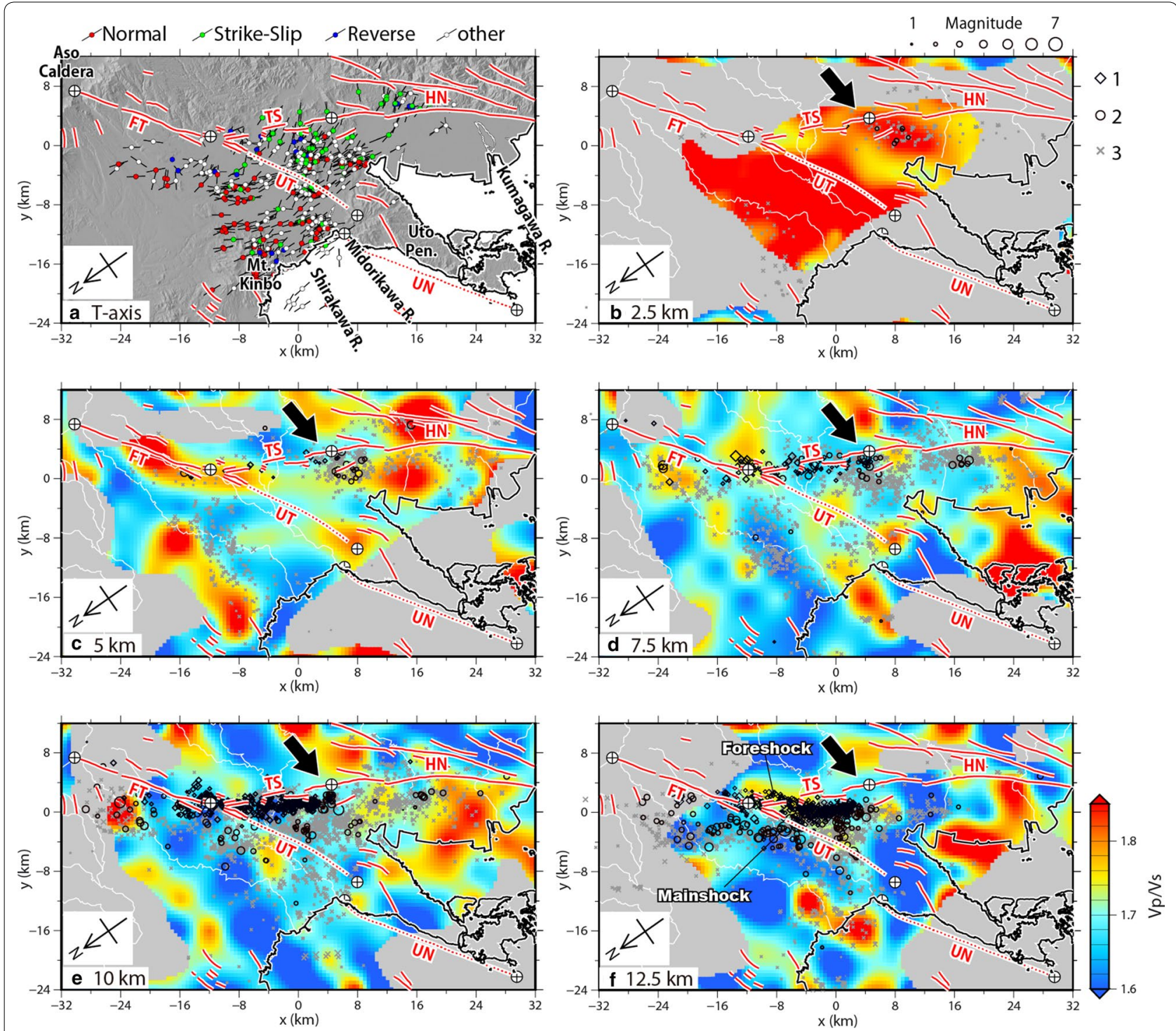

Fig. $6 \mathrm{Vp} / \mathrm{Vs}$ structure and aftershock distribution in the early stage. a T-axes of the various fault types, and Vp/Ns at b $2.5 \mathrm{~km}, \mathbf{c} 5 \mathrm{~km}, \mathbf{d} 7.5 \mathrm{~km}$, e $10 \mathrm{~km}$, and $\mathbf{f} 12.5 \mathrm{~km}$ depth. The hypocenters located within $2.5 \mathrm{~km}$ of each depth slice are plotted and labeled according to their occurrence in the earthquake sequence: 1 =from the foreshock to the mainshock; 2 = up to one day after the mainshock; 3 = April 17-June 30, 2016. The locations for 1-3 are based on the JMA unified earthquake catalog. The solid and dashed red lines denote the active faults determined by RGAF (1991) and HERP (2013), respectively. FT Futagawa segment, UT Uto segment, UN north coast of Uto Peninsula segment, TS Takano-Shirahata segment, HN Hinagu segment. The southern termination of the fault rupture, which is estimated during our study, is indicated by the black arrow

that the high-velocity body might have suppressed the southward propagation of the rupture along the Hinagu fault zone due to its high strength. The high-velocity body probably corresponds to the one we detected at point A in Fig. 7 since the velocities and locations are almost identical (Table 1). However, we believe that the 2016 earthquake rupture did not stop at this position because the slip amount in this area exceeds $1 \mathrm{~m}$ (Asano and Iwata 2016) and the aftershocks are spatially distributed across this area (Fig. 7b).

\section{Composition of the rocks in the seismogenic layer and rupture termination area}

Table 1 shows the velocities at rupture propagation point $A$ and rupture non-propagation point $B$, which reside on both sides of the velocity boundary. The change in velocity from point $\mathrm{A}$ to point $\mathrm{B}$ is distinct since $V \mathrm{p}$ increases while $V$ s decreases, which seems unusual. What rock types likely comprise these two distinct areas?

We illustrate the $V \mathrm{p}$ and $V \mathrm{~s}$ distributions at the 1710 relocated hypocenters in Fig. 8a, b, respectively, to 


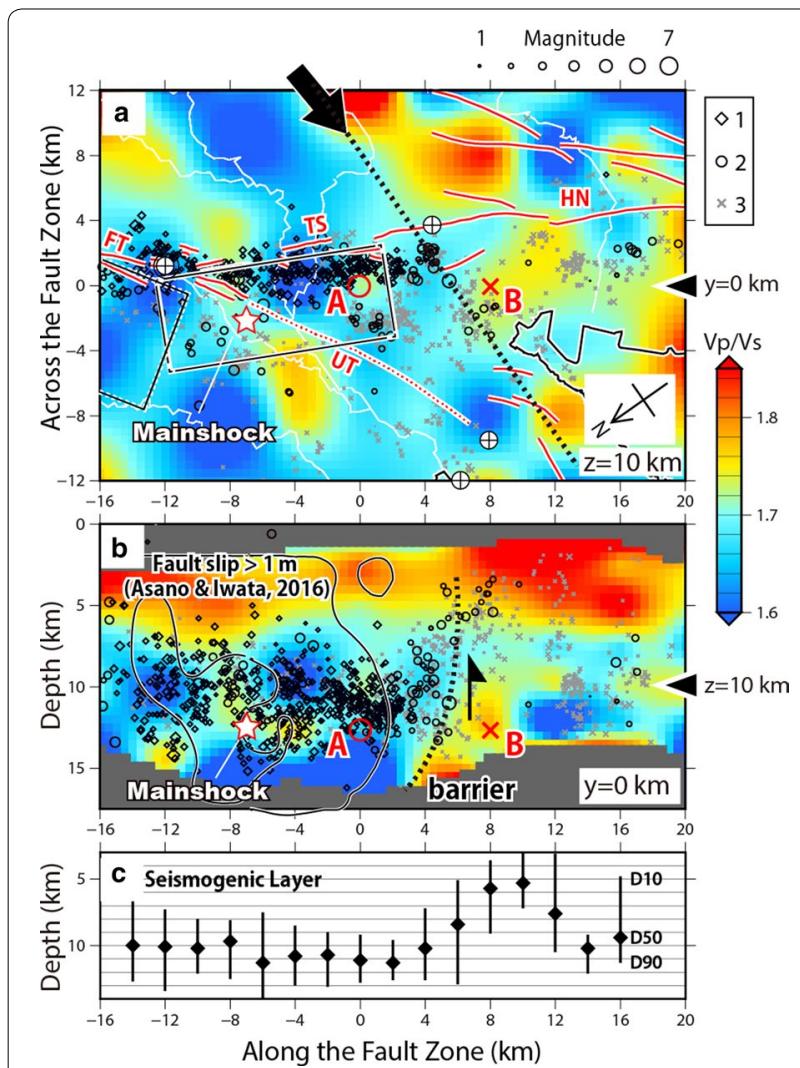

Fig. $7 \mathrm{Vp} / \mathrm{Vs}$ structure around the southern termination of the 2016 rupture. The symbols for the aftershocks indicate the same occurrence times as those in Fig. 6. a Vp/Vs structure at $10 \mathrm{~km}$ depth. The solid rectangles represent the surface expression of the source fault planes for the mainshock in Asano and Iwata (2016). The dashed black line and black arrow indicate the southern termination of rupture that was estimated in this study. The solid and dashed red lines denote the active faults determined by RGAF (1991) and HERP (2013), respectively. FT Futagawa segment, UT Uto segment, UN north coast of Uto Peninsula segment, TS Takano-Shirahata segment, HN Hinagu segment. b Vertical section of the Vp/Ns structure along the Hinagu fault zone $(y=0 \mathrm{~km})$. The hypocenters located in a range of $y=0-2 \mathrm{~km}$ are plotted. The black contour line shows the projected slip distribution (>1 m) of the mainshock (Asano and Iwata 2016). The dashed black line and black arrow indicate the southern termination of rupture that was estimated in this study. $\mathbf{c}$ Depth ranges of the hypocenters plotted in (b) at a 2-km interval. The top and bottom of each vertical line indicate D10 and D90, respectively, and each diamond indicates D50, where D10, D50, and D90 represent 10, 50, and $90 \%$ of the events occurred above those depths in each $2-\mathrm{km}$ interval

discuss the velocity ranges in the seismogenic layer. Approximately $80 \%$ of the values are in the 5.9-6.3 and $3.5-3.8 \mathrm{~km} / \mathrm{s}$ ranges for $V \mathrm{p}$ and $V \mathrm{~s}$, respectively, which is generally consistent with other observations in the seismogenic layer in Japan (Ito 1990; Iwasaki and Sato 2009). The velocities at rupture propagation point $A$ also fall within these ranges. Figure $8 \mathrm{c}$ illustrates the $V \mathrm{p}-V \mathrm{~s}$
Table 1 Seismic velocities obtained at rupture propagation point $A$ and rupture non-propagation point $B$

\begin{tabular}{lll}
\hline Point $(\boldsymbol{x}, \boldsymbol{y}, \boldsymbol{z})$ & $\mathbf{A}(\mathbf{0}, \mathbf{0 ,} \mathbf{1 2 . 5 )}$ & $\mathbf{B}(\mathbf{8}, \mathbf{0}, \mathbf{1 2 . 5})$ \\
\hline$V \mathrm{p}(\mathrm{km} / \mathrm{s})$ & 6.267 & 6.53 \\
$V_{s}(\mathrm{~km} / \mathrm{s})$ & 3.762 & 3.662 \\
$V p / V_{s}$ & 1.666 & 1.783 \\
$\sigma$ & 0.218 & 0.271 \\
\hline
\end{tabular}

The locations of $A$ and $B$ are shown in Fig. 7

$\sigma$, Poisson's ratio

relationship, and highlights that the earthquakes in our study area possess $V \mathrm{p} / V \mathrm{~s}$ values in the $1.62-1.74$ range (Poisson's ratio $=0.192-0.253$ ). The $V \mathrm{p} / V \mathrm{~s}$ range is relatively low throughout the upper to middle crust, which is consistent with the regional tomography results of Zhao et al. (2018). Figure 8c also shows the measured $V \mathrm{p}$ and $V$ s values for various rock types at $200 \mathrm{MPa}$ in the laboratory (Christensen 1996); $V \mathrm{p} / V \mathrm{~s}$ exceeds 1.75 for most of these rock samples, which does not correspond to most of $V \mathrm{p} / V \mathrm{~s}$ values from our study area. However, the $V \mathrm{p} / V \mathrm{~s}$ values for granitic rocks can be as low as 1.7 , which corresponds well with most of the $V \mathrm{p} / V \mathrm{~s}$ values from our study area. We therefore conclude that the seismogenic layer is likely composed of granite in our study area.

Conversely, the velocities at the rupture non-propagation point $\mathrm{B}$ are similar to those of diorite. Therefore, diorite is a potential candidate for the rock type present in the rupture termination area. However, partially serpentinized peridotite (marked 'q' in Fig. 8c) also plots near point $B$. The velocities of ultramafic rocks, such as dunite and peridotite, decrease as a result of serpentinization; the velocities fall between those of dunite and serpentine (Christensen 1966, 1996). The locations of dunite and the partially serpentinized peridotite samples (triangles) in Fig. 8c clearly illustrate this tendency. For example, the velocities of partially serpentinized peridotite decrease from ' $\mathrm{p}$ ' to ' $\mathrm{r}$ ' as the amount of serpentine increases from 29.4 to $52.7 \%$. Interpolation of these points suggests that the velocities at 'q' are indicative of $35 \%$ serpentinization. It is therefore highly likely that a serpentinized rock body exists at depth in this region since the Rokkoku Tectonic Line was intruded by serpentine and is now exposed at the surface. Watanabe et al. (2007) claimed that the high-T type of serpentine (containing antigorite) shows a lower Poisson's ratio than the low-T type of serpentine (containing lizardite and/or chrysotile) with the same density. The above-mentioned serpentinized peridotite samples by Christensen (1966) are low-T type. Although the serpentine exposed along the Rokkoku tectonic line is inferred as low-T type from the metamorphic condition of the northern part of the Manotani-Higo metamorphic complex (e.g., Osanai et al. 2006; Hirakawa and Uehara 


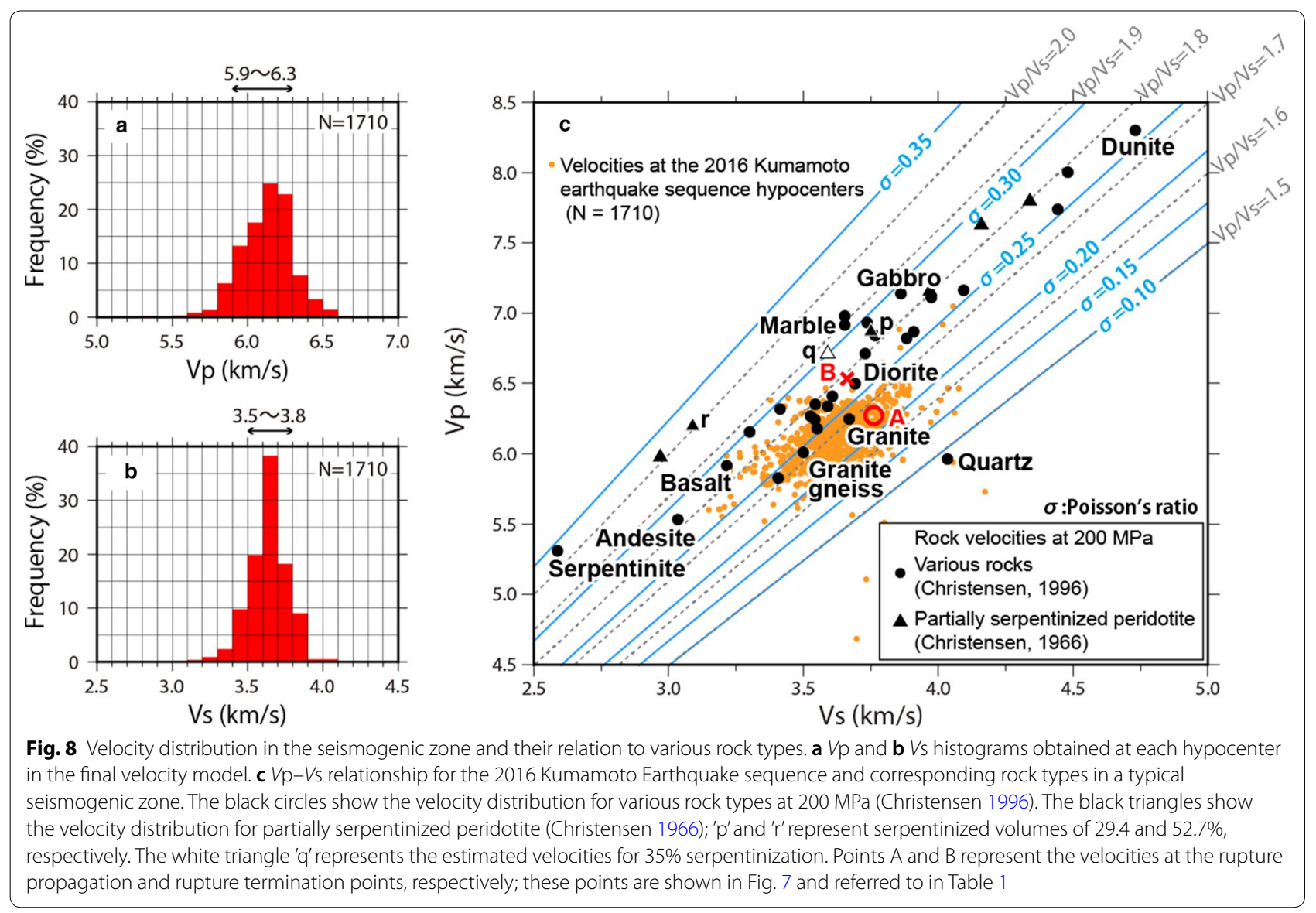

$2018)$, serpentinization would be higher $(\sim 80 \%)$ in case of high-T type (Watanabe et al. 2007).

The aftershocks during the initial stage did not occur in the high- $V \mathrm{p} / V \mathrm{~s}$ area at point $\mathrm{B}$, but they did occur in the southern low $-V \mathrm{p} / V \mathrm{~s}$ area to the south of $\mathrm{B}(x=16 \mathrm{~km}$ in Fig. 7). Furthermore, discontinuous postseismic deformation was detected by InSAR between April 18, 2016 and March 6, 2017 along the Hinagu segment where no coseismic deformation had been observed (Kobayashi 2018). These facts indicate that the stress change following the Kumamoto Earthquake occurred to the south of this high-Vp/Vs body, which may have acted as a relaxation barrier (King 1986). This type of barrier is more plausible if the high $-V \mathrm{p} / V \mathrm{~s}$ body consists of serpentinized rock because such a rock mass would cause weak coupling of the fault due to the ductility of serpentine (e.g., Kamiya and Kobayashi 2000). For example, serpentinized ultramafic rocks have been associated with creeping faults in central and northern California, and serpentine is commonly invoked as the cause of the creep and low strength of the most rapidly creeping section of the San Andreas Fault (Moore and Rymer 2007). It will be important to monitor the long-term postseismic deformation of the Hinagu fault zone to fully elucidate the composition of the rock barrier along the Hinagu Fault.

It is generally possible to use the cross-structure of a high- $V \mathrm{p} / V \mathrm{~s}$ body at seismogenic depths to assess the nature of structural boundaries, especially in areas where the hypocenter distribution terminates at the boundary of the high- $V \mathrm{p} / V_{\mathrm{s}}$ body. For example, we can identify another remarkable velocity boundary across the Hinagu fault zone between $\mathrm{HO}$ and LO in Fig. 5. The high-Vp/ Vs anomaly that crosses the Hinagu fault zone at depth might act as another barrier that terminates earthquake rupture. Additional paleo-seismological studies were conducted at several locations along the Hinagu fault zone after the 2016 earthquake, with one result indicating that the earthquake recurrence interval was shorter than that recognized before the earthquake (Miyashita 2018). The seismic velocity structure may help to improve the fault segmentation model inferred by faulting history, although more earthquake observations are required for using as a quantitative index of the barriers to rupture propagation. Numerical analyses of dynamic rupture propagation in heterogeneous materials will provide useful insights when trying to judge whether such 
inhomogeneous barriers can terminate the rupture of larger M 8 events.

\section{Conclusions}

We imaged the detailed seismic velocity structure around the southern termination of the 2016 Kumamoto Earthquake rupture using local seismic tomography. The $V \mathrm{p}$ and $V \mathrm{p} / V \mathrm{~s}$ structures clearly revealed several zonal anomalies that were oriented E-W and ENE-WSW at seismogenic depths. The zonal bodies were relatively continuous in the vertical direction since the surface projections of the velocity anomalies were almost the same at different depths. The focal mechanisms along the margins of the zonal bodies suggested that some structural boundaries were activated as normal faults.

The relocated aftershocks occurred in areas where the velocities for approximately $80 \%$ of the aftershocks were in the 5.9-6.3 and 3.5-3.8 km/s ranges for $V p$ and $V \mathrm{~s}$, respectively. The $V \mathrm{p} / V \mathrm{~s}$ values were relatively low $(1.62-1.74$, or Poisson's ratio $=0.192-0.253)$, which indicate that the seismogenic layer is likely composed of granite in the study area. Aftershocks did not occur in the areas with higher $V \mathrm{p} / V \mathrm{~s}$ values. The southern margin of the mainshock rupture and the aftershock distribution during the initial stage correspond to a velocity boundary with a high- $V \mathrm{p} / V \mathrm{~s}$ body on the southern side. The depth of the seismogenic layer clearly changes at this boundary.

The main factor that controlled the southern rupture termination of the 2016 Kumamoto Earthquake was the presence of a high- $V \mathrm{p} / V \mathrm{~s}$ body that acted as a barrier to continued rupture. This velocity boundary corresponds to the E-W-trending Rokkoku Tectonic Line, which was intruded by serpentine, and probably caused the vertical offset of the seismogenic layer at depth. Such information on inhomogeneous barriers, which can be inferred from the seismic velocity structure, may assist in improving seismic hazard assessments.

\section{Supplementary information}

Supplementary information accompanies this paper at https://doi. org/10.1186/s40623-020-01276-1.

Additional file 1: Figure S1. Checkerboard test results for the Vp structure at (a) $0 \mathrm{~km}$, (b) $2.5 \mathrm{~km}$, (c) $5 \mathrm{~km}$, (d) $7.5 \mathrm{~km}$, (e) $10 \mathrm{~km}$, and (f) $12.5 \mathrm{~km}$ depth. The derivative weighted sum (DWS) that shows a ray-path density of $>500$ is defined by the area surrounded by the yellow line. The abbreviations for the fault segments are the same as on Fig. 1. The southern termination of the fault rupture, which is estimated during our study, is indicated by the black arrow.

Additional file 2: Figure S2. Checkerboard test results for the Vs structure at (a) $0 \mathrm{~km}$, (b) $2.5 \mathrm{~km}$, (c) $5 \mathrm{~km}$, (d) $7.5 \mathrm{~km}$, (e) $10 \mathrm{~km}$, and (f) $12.5 \mathrm{~km}$ depth. The derivative weighted sum (DWS) that shows a ray-path density of $>500$ is defined by the area surrounded by the yellow line. The figure is the same as Figure S1, but for the Vs structure.
Additional file 3: Figure S3. Checkerboard test results for the Vp (left) and $V_{s}$ (right) structure in the vertical cross-sections at $y=-4,0,4 \mathrm{~km}$. The derivative weighted sum (DWS) that shows a ray-path density of $>500$ is defined by the area surrounded by the yellow line.

Additional file 4: Figure S4. Hypothesis testing results for the Vp/Vs structure. (Left) Inversion results for a horizontally layered synthetic model. (Right) Inversion results for a synthetic model with partially high Vp/ $V s$ patch. $V p$ and $V s$ values at three grid nodes were given to the same synthetic model, based on the final 3-D model (Figs. 5 and S5), as follows: $V p=6.16 \mathrm{~km} / \mathrm{s}$ and $V s=3.54 \mathrm{~km} / \mathrm{s}$ at $(x, y, z)=(8,0,10), V p=6.53 \mathrm{~km} / \mathrm{s}$ and $V s=3.67 \mathrm{~km} / \mathrm{s}$ at $(8,0,12.5), V p=6.38 \mathrm{~km} / \mathrm{s}$ and $V s=3.60 \mathrm{~km} / \mathrm{s}$ at $(4$, $0,15)$.

Additional file 5: Figure S5. S-wave velocity structure and relocated hypocenters in this study. The figure is the same as Fig. 5, but for the Vs structure.

\section{Abbreviations}

HERP: Headquarters for Earthquake Research Promotion; UYTL: Usuki-Yatsushiro Tectonic Line; OKTL: Oita-Kumamoto Tectonic Line; BSG: Beppu-Shimabara Graben; UT: Uto segment; UN: North coast of the Uto segment; FT: Futagawa segment; TS: Takano-Shirahata segment; HN: Hinagu segment; YT: Yatsushiro Sea segment; JMA: Japan Meteorological Agency; RGHFSE: Research Group for the 2003 Hinagu Fault Seismic Expedition; CRT: Checkerboard resolution test; DWS: Derivative weighted sum.

\section{Acknowledgements}

The tomographic inversion was conducted using "tomoDD" program developed by Zhang and Thurber (2003). The JMA unified earthquake catalog, which is produced by JMA in cooperation with the Ministry of Education, Culture, Sports, Science, and Technology (MEXT), was provided by JMA. The travel-time data obtained by the 2003 seismic expedition were provided by the Research Group for the 2003 Hinagu Fault Seismic Expedition (2008). We thank two anonymous reviewers and editor Takuji Yamada for their helpful comments and suggestions on improving the manuscript. All of the figures were produced using the Generic Mapping Tools software (Wessel and Smith 1998). We would like to express our deep gratitude to all the parties concerned.

\section{Authors' contributions}

YA planned this study, analyzed the data and drafted the manuscript. YA and HK participated in data acquisition. YA and KM participated in discussion on rupture termination. KM contributed to revise abstract. All authors read and approved the final manuscript.

\section{Funding}

This work was supported by the Central Research Institute of Electric Power Industry (CRIEPI) under its "Rational evaluation of earthquake source fault corresponding to active fault" program.

\section{Availability of data and materials}

The datasets used and/or analyzed during the current study are available from the corresponding author on reasonable request.

\section{Competing interests}

The authors declare that they have no competing interests.

Received: 23 June 2020 Accepted: 18 September 2020

Published online: 07 October 2020

\section{References}

Aki K (1979) Characterization of barriers on an earthquake fault. J Geophys Res 84(B11):6140-6148

Asano K, Iwata T (2016) Source rupture processes of the foreshock and mainshock in the 2016 Kumamoto Earthquake sequence estimated from the kinematic waveform inversion of strong motion data. Earth Planets Space 68:147. https://doi.org/10.1186/s40623-016-0519-9 
Christensen NI (1966) Elasticity of ultrabasic rocks. J Geophys Res 71(24):5921-5931

Christensen NI (1996) Poisson's ratio and crustal seismology. J Geophys Res 101(B2):3139-3156

Frohlich C (1992) Triangle diagrams: ternary graphs to display similarity and diversity of earthquake focal mechanisms. Phys Earth Planet Inter 75:193-198

Fukuyama E, Ishida M, Dreger DS, Kawai H (1998) Automated seismic moment tensor determination by using on-line broadband seismic waveforms. J Seismol Soc Jpn 51:149-156 (in Japanese with English abstract)

Geological Survey of Japan (ed.) (1995) Geological Map of Japan 1:1,000,000, 3rd Edition, CD-ROM version. Digital Geoscience Map G-1, Geological Survey of Japan.

Goto H, Tsutsumi H, Toda S, Kumahara Y (2017) Geomorphic features of surface ruptures associated with the 2016 Kumamoto earthquake in and around the downtown of Kumamoto City, and implications on triggered slip along active faults. Earth Planets Space 69:26. https://doi.org/10.1186/ s40623-017-0603-9

Headquarters for Earthquake Research Promotion (HERP) (2013) Long-term evaluation of the Futagawa and Hinagu fault zones (partly revised) (in Japanese). https://www.jishin.go.jp/main/chousa/katsudansou_pdf/93_ futagawa_hinagu_2.pdf Accessed 22 June 2020

Hirakawa M, Uehara S (2018) Microstructure of serpentine minerals in Chikuyoseki" from Matsubasemachi, Uki, Kumamoto prefecture, Japan. Japan Geoscience Union Meeting 2018 abstracts, SCG60-P01. https ://confit.atlas.jp/guide/event-img/jpgu2018/SCG60-P01/public/ pdf?type=in\&lang=en

Himematsu Y, Furuya M (2016) Fault source model for the 2016 Kumamoto earthquake sequence based on ALOS-2/PALSAR-2 pixel-offset data: evidence for dynamic slip partitioning. Earth Planets Space 68:169. https ://doi.org/10.1186/s40623-016-0545-7

Hirata N, Matsu'ura M (1987) Maximum-likelihood estimation of hypocenter with origin time eliminated using nonlinear inversion technique. Phys Earth Planet Inter 47:50-61

Ito K (1990) Regional variations of the cutoff depth of Seismicity in the crust and their relation to heat flow and large inland-earthquakes. J Phys Earth 38:223-250

Iwasaki T, Sato H (2009) Crust and uppermantle structure of island arc being elucidated from seismic profiling with controlled sources in Japan. J Seismol Soc Jpn 61:S165-S176 (in Japanese with English abstract)

Kamata H (1989) Volcanic and structural history of the Hohi volcanic zone, central Kyushu, Japan. Bull Volcanol 51:315-332

Kamata H, Kodama K (1994) Tectonics of an arc-arc junction: an example from Kyushu Island at the junction of the Southwest Japan Arc and the Ryukyu Arc. Tectonophysics 233:69-81

Kamiya S, Kobayashi Y (2000) Seismological evidence for the existence of serpentinized wedge mantle. Geophys Res Lett 27(6):819-822

Kimura M (1983) Formation of Okinawa Trough grabens. Mem Geol Soc Jpn 22:141-157 (in Japanese with English abstract)

King GCP, Nabelek JL (1985) Role of fault bends in the initiation and termination of earthquake rupture. Science 228:984-987

King GCP (1986) Speculations on the geometry of the initiation and termination processes of earthquake rupture and its relation to morphology and geological structure. Pure Appl Geophys 124:567-585

Kobayashi T (2017) Earthquake rupture properties of the 2016 Kumamoto earthquake foreshocks (Mj 6.5 and Mj 6.4) revealed by conventional and multiple-aperture InSAR. Earth Planets Space 69:7. https://doi. org/10.1186/s40623-016-0594-y

Kobayashi T, Yarai H, Kawamoto S, Morishita Y, Fujiwara S, Hiyama Y (2018) Crustal Deformation and Fault Models of the 2016 Kumamoto Earthquake Sequence: Foreshocks and Main Shock. In: Freymueller J, Sánchez L (eds) International Symposium on Advancing Geodesy in a Changing World. International Association of Geodesy Symposia. Springer, Cham, pp 193-200

Kobayashi T (2018) Postseismic deformation of the 2016 Kumamoto Earthquake. The report of the Coordinating Committee for Earthquake Prediction 100:405-408(in Japanese)

Matsumoto N, Hiramatsu Y, Sawada A (2016) Continuity, segmentation and faulting type of active fault zones of the 2016 Kumamoto earthquake inferred from analyses of a gravity gradient tensor. Earth Planets Space 68:167. https://doi.org/10.1186/s40623-016-0541-y
Matsumoto S, Nakao S, Ohkura T, Miyazaki M, Shimizu H, Abe Y, Inoue H, Nakamoto M, Yoshikawa S, Yamashita Y (2015) Spatial heterogeneities in tectonic stress in Kyushu, Japan and their relation to a major shear zone. Earth Planets Space 67:172. https://doi.org/10.1186/s4062 3-015-0342-8

Matsumoto Y (1979) Some problems on volcanic activities and depression structures in Kyushu, Japan. Mem Geol Soc Jpn 16:127-139 (in Japanese with English abstract)

Miyakawa A, Sumita T, Okubo Y, Okuwaki R, Otsubo M, Uesawa S, Yagi Y (2016) Volcanic magma reservoir imaged as a low-density body beneath ASO volcano that terminated the 2016 Kumamoto earthquake rupture. Earth Planets Space 68:208. https://doi.org/10.1186/ s40623-016-0582-2

Miyashita Y (2018) The 2016 Kumamoto Earthquake and paleoearthquake history of the Hinagu fault zone. The report of the Coordinating Committee for Earthquake Prediction 100:380-385(in Japanese)

Moore DE, Rymer MJ (2007) Talc-bearing serpentinite and the creeping section of the San Andreas fault. Nature 448:795-797

Osanai Y, Owada M, Kamei A, Tamamoto T, Kagami H, Toyoshima T, Nakano N, Nam TN (2006) The Higo metamorphic complex in Kyushu, Japan as the fragment of Permo-Triassic metamorphic complexes in East Asia. Gondwana Res 9:152-166

Pizzi A, Galadini F (2009) Pre-existing cross-structures and active fault segmentation in the northern-central Apennines (Italy). Tectonophysics 476:304-319

Reasenberg P, Oppenheimer DH (1985) FPFIT, FPPLOT AND FPPAGE; Fortran computer programs for calculating and displaying earthquake fault-plane solutions, U.S.G.S Open-File Report 85-739. doi https://doi.org/10.3133/ ofr85739

Research Group for Active Faults of Japan (RGAF) (1991) Active faults in Japan: sheet maps and inventories (revised edition). University of Tokyo Press (in Japanese)

Research Group for the 2003 Hinagu Fault Seismic Expedition (RGHFSE) (2008) Seismic expedition in the Hinagu fault area, Kyusyu island, Japan. Bull Earthq Res Inst Univ Tokyo 83:103-130 (in Japanese with English abstract)

Saito M, Takarada S, Toshimitsu S, Mizuno K, Miyazaki K, Hoshizumi H, Hamasaki S, Sakaguchi K, Ohno T, Murata Y (2010) Geological Map of Japan $1: 200,000$, Yatsushiro and a part of Nomo Zaki. Geological Survey of Japan, AIST

Shirahama Y, Yoshimi M, Awata Y, Maruyama T, Azuma T, Miyashita Y, Mori H, Imanishi K, Takeda N, Ochi T, Otsubo M, Asahina D, Miyakawa A (2016) Characteristics of the surface ruptures associated with the 2016 Kumamoto earthquake sequence, central Kyushu, Japan. Earth Planets Space 68:191. https://doi.org/10.1186/s40623-016-0559-1

Shito A, Matsumoto S, Shimizu H, Ohkura T, Takahashi H, Sakai S, Okada T, Miyamachi H, Kosuga M, Maeda Y, Yoshimi M, Asano Y, Okubo M (2017) Seismic velocity structure in the source region of the 2016 Kumamoto earthquake sequence, Japan. Geophys Res Lett 44:7766-7772

Tada T (1984) Spreading of the Okinawa Trough and its relation to the crustal deformation in Kyusyu. J Seismol Soc Jpn 37:407-415 (in Japanese with English abstract)

Toda S, Stein R (2019) Ridgecrest earthquake shut down cross-fault aftershocks. Temblor. https://doi.org/10.32858/temblor.043

Ueno H, Hatakeyama S, Aketagawa T, Funasaki J, Hamada N (2002) Improvement of hypocenter determination procedures in the Japan Meteorological Agency. Quarter J Seismol 65:123-134 (in Japanese with English abstract)

Urabe T, Tsukada S (1991) A workstation-assisted processing system for waveform data from microearthquake networks. Abst Spring Meet Seismol Soc Jpn 70 (in Japanese)

Waldhauser F, Ellsworth WL (2000) A double-difference earthquake location algorithm: method and application to the northern Hayward Fault. California Bull Seismol Soc Am 90(6):1353-1368

Watanabe T, Kasami H, Ohshima S (2007) Compressional and shear wave velocities of serpentinized peridotites up to $200 \mathrm{MPa}$. Earth Planets Space 59:233-244

Wessel P, Smith WHF (1998) New, improved version of the generic mapping tools released. EOS Trans Am Geophys Union 79(47):579 
Yabe H (1925) The "Nagasaki Dreiecke" proposed by Prof. Richthofen ("Richthofen-shi no Nagasaki-sankaku-chiiki" in Japanese). J Geol Soc Jpn 32:201-209 (in Japanese)

Yanagida J (1958) The Upper Permian Mizukoshi Formation. J Geol Soc Jpn 64:222-231 (in Japanese with English abstract)

Yue H, Ross ZE, Liang C, Michel S, Fattahi H, Fielding E, Moore A, Liu Z, Jia B (2017) The 2016 Kumamoto Mw = 7.0 Earthquake: A Significant Event in a Fault-Volcano System. J Geophys Res 122:9166-9183

Zhang H, Thurber CH (2003) Double-difference tomography: The method and its application to the Hayward fault, California. Bull Seismol Soc Am 93(5):1875-1889
Zhao D, Yamashita K, Toyokuni G (2018) Tomography of the 2016 Kumamoto earthquake area and the Beppu-Shimabara graben. Sci Rep 8:15488. https://doi.org/10.1038/s41598-018-33805-0

\section{Publisher's Note}

Springer Nature remains neutral with regard to jurisdictional claims in published maps and institutional affiliations.

\section{Submit your manuscript to a SpringerOpen ${ }^{\circ}$ journal and benefit from:}

- Convenient online submission

- Rigorous peer review

- Open access: articles freely available online

- High visibility within the field

- Retaining the copyright to your article

Submit your next manuscript at $\boldsymbol{\nabla}$ springeropen.com 